\title{
Playing (in) a Crisis Simulation
}

\section{What is the Playful Engagement in a Serious Simulation Made of?}

\author{
David Goutx ${ }^{1(\bowtie)}$, Sophie Sauvagnargues ${ }^{1}$, and Laurent Mermet $^{2}$ \\ ${ }^{1}$ Institut Mines Alès, 6 Avenue de Clavières, 30100 Ales, France \\ david.goutx.pro@gmail.com \\ ${ }^{2}$ MNHN (muséum national d'histoire naturelle), jardin des plantes, \\ 57 rue Cuvier, 75005 Paris, France
}

\begin{abstract}
The nature and the varying levels of the engagement of participants with a crisis management exercise still cannot be described properly by the usual evaluation tools of the users' experiences nor does the application of the concept of flow help either.

The author proposes a protocol to do a qualitative analysis of video taken during crisis management exercises, based on the premise that emotional outbursts (laughter, swearwords,..) betray an excess of tension between the applied convention of pretending, by which the participants act like the simulation is a burdensome reality, and the always present knowledge that it is only a game.

This protocol is tested on two crisis management exercises played in a simulation room. It confirms the concept of ludicity - a component of the simulation, created by the participants on top of what is needed for the good progress of the simulation-, the proposal of a typology, which is used to analyse the impact on the simulation of the injection of new events and the possibility that the playfulness of the simulation is subject to entropy.
\end{abstract}

Keywords: Simulation $\cdot$ Ludicity $\cdot$ Engagement $\cdot$ Videoanalysis $\cdot$ Codification

\section{Introduction}

The learning benefits of engagement in a simulation are well known. The tools of play have been marshalled in various approaches mixing play and serious learnings, like serious games or gamification. They are the subject of a vast body of work which systematically shows, often thanks to evaluation after the end of the simulation, that learnings are heightened when playfulness is present.

Few works address what happens during the simulation, either to learnings or to the playful engagement, even though it is essential to determine if playing well in a simulation means learning well in the real world [1].

Using the exploration of two crisis management exercises, this article presents a way to analyse the components of the participants' playful engagement relying on a codification of the manifestations of playfulness and the proposal of a typology. 


\section{Theoretical Framework and Bibliographical Review}

\subsection{Play in Crisis Management Exercises}

We are looking at crisis management exercises, which become games as soon as they require the participants to engage their imagination to believe they are in a real crisis.

The simulation's participants agree on the meaning they give to the information they interact with during the course of the simulation. This collective agreement forms a liminal space in which the simulation unfolds its reality with the active consent of the participants $[2,3]$.

The participants activate the procedures expected for the circumstances, but also, they create an original performance of the simulated crisis. As Klabbers [4] states: " $A$ game is not a neutral communication medium. The primary function of gaming is not information transfer, but influencing thought and action". We give the name ludicity to this 'non-neutral' component of the simulation, created by the participants on top of what is needed for the good progress of the simulation [5]. It is close to the jouabilité of Henriot [6] or the lusory attitude of Suits [7].

Thus defined, ludicity is the part of the liminal space containing the emotions born in the simulation and unfolding during its development.

\subsection{A Blind Spot in the Optimal Engagement in the Flow}

The link between the presence of playful elements in a pedagogical exercise and the quality of the learnings, is regularly shown in publications, to the point that it is now usual to introduce playful elements in all types of activities - This is known as Gamification [8].

Numerous publications, influenced by the notion of flow -the optimal experience of total commitment to the task at hand $[9,10]$ are built on questionnaires given to players at the end of a session, appraising the components of the flow [15].

First described for athletes then extended to other situations which require a high performance, the concept of flow does not enable us to properly identify the pleasure created by play which is felt by the members of a group who face together a fictional situation without individual challenges. Furthermore, it is not well adapted to a game of simulation, in which the commitment, however intense, is always linked to a certain analytical distance as the participant plays while knowing he is playing [26].

\subsection{Pleasures and Emotions from Play}

The pleasure and the emotions created by play, even more than commitment itself mentioned so often than its meaning is less clear [11] - play a key role in learning from a simulation. Faced with the failures of some Serious Games, Alvarez and Djaouti [12] reminds the creators of such games that they must not neglect the player's pleasure. 
Paradoxically, the pleasure from play still is a rather vague concept, especially when compared to flow with its precise breakdown into nine components. From his observation of Live Action Role Playing (LARP) games, Kapp [13] defines it as the contentment the player derived from properly playing his role and assisting in the good development of the game.

The engagement of players with their characters, group and adventures has been evaluated in role playing games [14], after the end of the game. It is confronted with two intertwined problems [15]: first, a questionnaire at the end of the game does not capture the constant variation of the engagement during the game and second, measuring the engagement of a player during the game can unsettle the very engagement we were trying to observe.

Mullins \& Sabherwal [16] propose a blueprint to explore the emotions linked to the player's engagement in a game. But it is difficult to observe emotions. It has been shown that protocols used to assign emotions when looking at pictures of faces were skewed by the subjectivity of the observers [17]. Most of the objective systems used to observe emotions, like heat sensors detecting changes in temperature of the hands or face, reduce the emotions captured to fear and stress [18].

Finally following Kapp [13], the best way to feel the emotions within a LARP game is to be playing among the players.

\subsection{Selected Issue: From Fun in Games to Fun in Simulations}

Rather than trying to continuously identify emotions during the simulation, our approach is to analyse the playful moments marked by emotional outbursts.

Indeed, during a crisis management exercise, mastering your emotions is recommended as they are seen to skew rational decisions. Emotions can even be feared for moving the simulation away from its objective of realism [19]. The sudden appearance of a smile, or even laughter or swearwords, is an incongruous sign that some tension pent-up inside the player has been released. This tension comes (according to Goffman [20]) from the efforts made by the player to keep up the appearances of the social (or here the game) convention he is part of, when he is conscious of an offset between this social convention and other realities.

We thus consider these smiles, laughs and swearwords as objective indicators of an emotional outburst (Goffman's flooding) revealing the tension accrued inside the player trying to maintain the convention of pretending in the simulation. These outbursts are also an attempt to push some other players to share in the outburst as a mean to reduce the tension.

\section{Mechanism of the Experiment}

\subsection{Presentation of the Simulations and Simulation Room}

The simulation room we used was built in 2011 in the IMT Mines d'Ales, following the work of Dautun [21], as a research platform in which it is possible to develop and test different devices, to immerse trainees in crisis situations, isolating them in a room representing a crisis unit. 
Two rooms for the trainees are furnished like a town crisis management centre, while the facilitators stand in a control room (Fig. 1). The software Simul'Crises [22] enables the scenario of the simulated crisis to unfold, adapting the number of incidents to the level of mastery of the players, while maintaining some freedom of action for the players.

The simulations last for two hours. The team leading the simulation collects information on the players' actions through the phone calls it receives from the players but also thanks to observers present in the rooms.

The two simulations observed are based on the same scenario: the participants have been summoned to the crisis management centre because of a road traffic accident between a car and a heavy goods vehicle transporting chlorine cylinders which have spilled onto the road. The players must first make the local population under the threat of the toxic gas, take refuge inside, then face an accidental forest fire that forces the evacuation of the population. The two simulations differ only in the profiles of the participants (Table 1).

Table 1. General characteristics of the participants.

\begin{tabular}{l|l|l|l|l|l|l|l|l}
\hline \multirow{2}{*}{} & \multicolumn{3}{|l|}{ Simulation 16V2017 } & \multicolumn{3}{l}{ Simulation 15VI2017 } \\
\cline { 2 - 9 } & Average & $\begin{array}{l}\text { Standard- } \\
\text { deviation }\end{array}$ & $\begin{array}{l}\text { Average } \\
\text { (Male) }\end{array}$ & $\begin{array}{l}\text { Average } \\
\text { (Female) }\end{array}$ & Average & $\begin{array}{l}\text { Standard- } \\
\text { deviation }\end{array}$ & $\begin{array}{l}\text { Average } \\
\text { (Male) }\end{array}$ & $\begin{array}{l}\text { Average } \\
\text { (Female) }\end{array}$ \\
\hline Age & 21,32 & 0,75 & 21,00 & 22,00 & 33,7 & 9,6 & 34,80 & 31,50 \\
\hline Number & 16 & & 12 & 4 & 13 & & 9 & 4 \\
\hline
\end{tabular}

\subsection{System of Observation}

Observing the moment of ludicity relies on audio and video recording made -with the consent of the players - with tripod mounted stationary cameras (Fig. 1) which capture most of the players' activities from different angles without pre-selecting areas of interest [23].

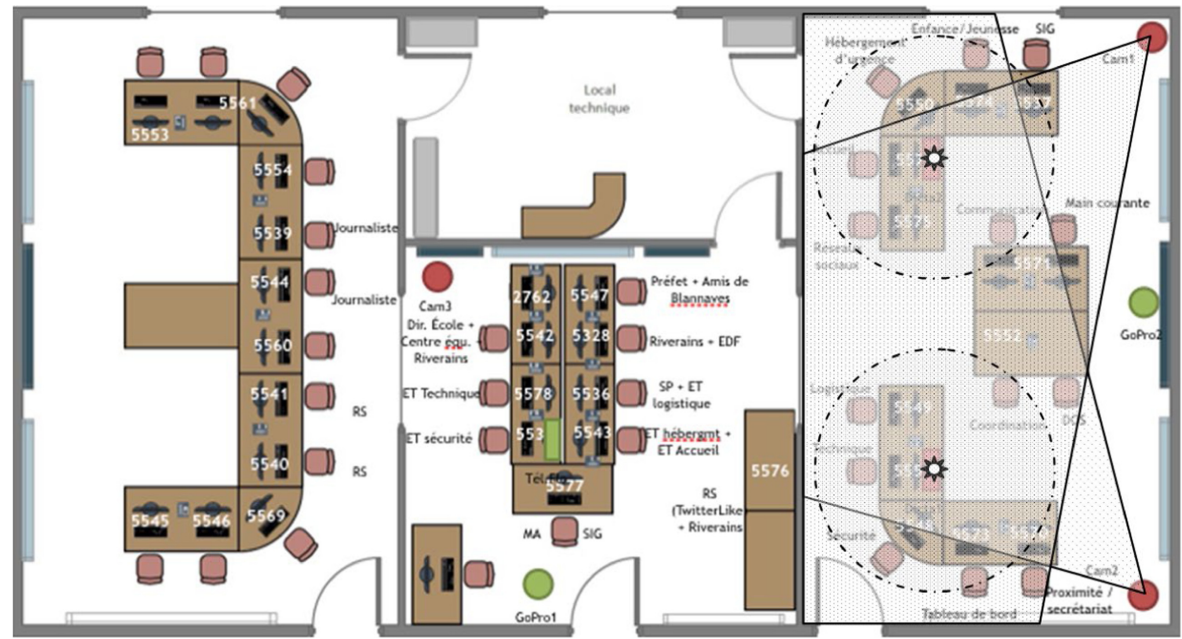

Fig. 1. Experimental installation with video cameras (red circles with field of view) and audiorecorders (black stars with approximate range). (Color figure online) 
The machinary isn't hidden, but the players pay little attention to it during the simulation.

\subsection{Methodology of the Analysis}

The method retained to analyze the recordings is inspired by the qualitative analysis of video [23, 24]: using selection criteria chosen beforehand for their significance, the chosen recordings are screened several times, each time from a different point of view, then reconciling all the analysis of the same sequence.

Concretely the recording are analyzed as follow:

1. During the first viewing, the smiles, laughs, swearwords are detected and help define the sequences to be analyzed (Fig. 2).

2. Each defined sequence is then screened as many times as they are participants in the gameplay resulting in the emotional outburst.

3. Each defined sequence is described through content logs [23] in a way that enables us to infer the causes of the emotional outburst using the concept of ludicity [5].

4. The causes are written down trying to group what seems similar and their linking helps creates categories and subsequently a first attempt at a typology.

5. The typology is employed to codify minute per minute the emotional outburst throughout each simulation (Fig. 3) and to allow analysis.

Ludicity as we defined it has a collective component: the persons who manifest it try to share their emotions with the others around them by creating a form of fellowship. The codification of the ludicity bears that out: we analyse with the same system the player who creates this manifestation of ludicity and the players who share in it.
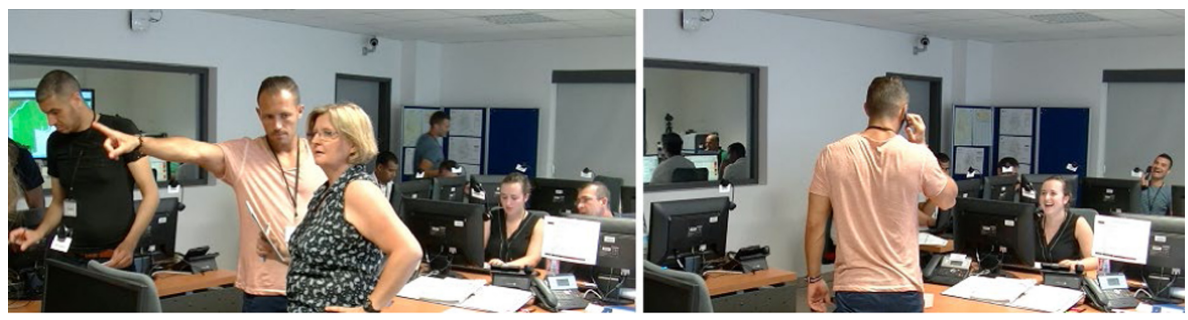

Fig. 2. Screenshots from a simulation: serious activity (left) vs. Emotional outburst (right).

\section{Results}

\subsection{Density of Ludicity}

The density of the ludicity in the simulation is evaluated (Fig. 3, Table 2) through:

- The one dimensional ludicity, i.e. the ratio of the length of the simulation marked by at least one player manifesting ludicity to the overall length of the simulation. 
- The two dimensional ludicity, i.e. the ratio of the space of ludicity (number of players $x$ the length of ludicity) to the overall space of the simulation.

These metrics (based on just two simulations) suggest that a significant part (around $13.5 \%$ ) of the actions of the players is dedicated to the ludicity which does not participate in the rational crisis management.

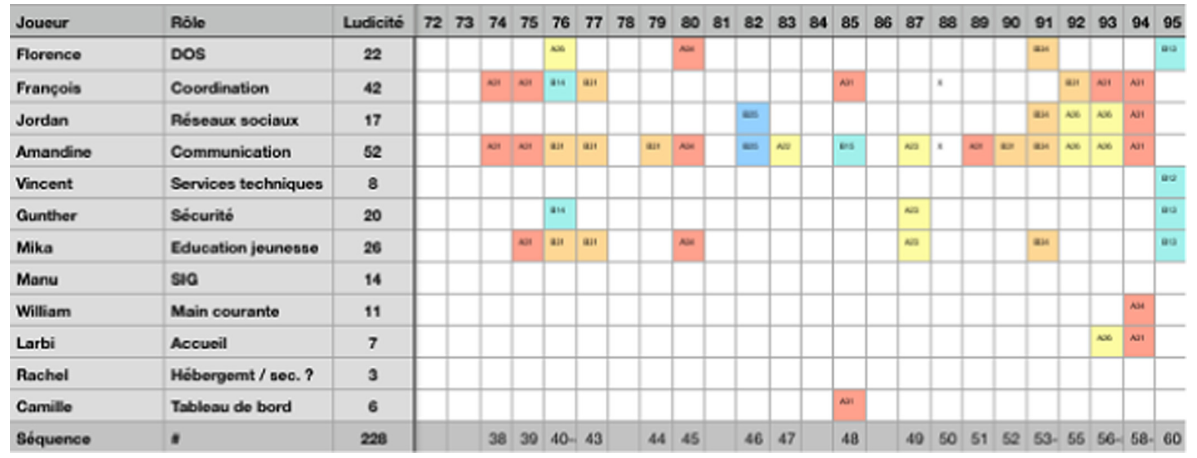

Fig. 3. Example of codification template - zoom on the $72^{\text {nd }}$ to $95^{\text {th }}$ minute portion of the 15VI2017 simulation with a coloured codification of the types of ludicity detected (see Sect. 4.2 for details): players (with role played and total number of minutes of ludicity detected) in the three first columns on the left, each of the other columns corresponds to a minute of simulation; in white, the minutes without any occurrence of ludicity for a given player. Here, 1Dludicity $=75 \%$ (18 columns out of 24 showing ludicity for at least one player), 2Dludicity $=17 \%$ (48 cells out of 288 showing ludicity for a player within a minute).

Table 2. Basic metrics of ludicity detected in the simulations records.

\begin{tabular}{l|l|l}
\hline & $\begin{array}{l}\text { Simulation } \\
\text { 16V2017 }\end{array}$ & $\begin{array}{l}\text { Simulation } \\
15 \mathrm{VI} 2017\end{array}$ \\
\hline Total duration recorded (min) & 104 & 135 \\
\hline Cumulated playfulness sequences duration (min) & 37 & 71 \\
\hline $\begin{array}{l}\text { 1-dimensional Rate of Ludicity } \\
\begin{array}{l}\text { Total 2-dimensional game space recorded (players } \\
\text { x min) }\end{array}\end{array}$ & $35.6 \%$ & $52.6 \%$ \\
\hline $\begin{array}{l}\text { Cumulated 2-dimensional playfulness space } \\
\text { (players x min) }\end{array}$ & 1040 & 1620 \\
\hline \begin{tabular}{l} 
2-dimensional Rate of Ludicity \\
\hline
\end{tabular} & $12.9 \%$ & 228 \\
\hline
\end{tabular}

\subsection{Towards a Typology of Ludicity}

As an attempt to make our ludicity concept as structured as the flow concept, we created a typology of the manifestations of ludicity, with two main categories: 
- The ludicity linked to the game environment (A)

- The ludicity linked the in-game attitudes of the players (B)

Among the manifestations of (A), we distinguish between:

- The ones relating to the liminal space-time (A1), combining the start time of the simulation by which the players show their entry into the simulation, the agglutination of the collective liminal space from the individual agreement of each player to respect the convention of pretending, the integration of external information by which the players integrate in the liminal space, additional information coming from outside [3, 4] and the reunification of the liminal space after a schism;

- The ones relating to dissonances (A2), whether they are between the representation the players have of the fictional situation and the ones the people leading the simulation have [24], to the dislocation of the liminal space because of the disagreement on the interpretation of the fictional situation in the same simulation room, to a divergence in the assignment of meaning when a new external information is understood differently by two players [3, 4], to a defect in the game paraphernalia disturbing the fluid development of the simulation, to a subpar mastery of the game information when the player is not efficient at acting in the simulation, or to the loss of credibility of the simulation because of its perceived poor relationship to reality;

- The ones relating to stepping away from the game (A3) which encompass the corrosive manifestations of jests trying to amuse one's fellow players with the content of the simulation in reference to a context from outside the simulation [20], to the distraction game-in which uses an element of the simulation for a joke in a context internal to the simulation that distracts the other players [20], to the temptation of game breaker which reflect intentional acts of sabotage of the convention of pretending and of the liminal space [25] or to behaving as a spectator when the player sits there observing without participating in the game [26].

Among the manifestations of (B), we distinguish:

- The ones relating to the pleasure from play (B1) from the exploration of the limits of the game and the freedom to act within these limits, to a form of irony game-in when a player as his character teases another character for his actions in the game, to the exhilaration derived from the role-play when the role player becomes more of an actor and the character's actions start to feel real [13], to overcoming a difficulty which corresponds to a form of flow, or to the soothing of some anguish which is supposed to rise among the player;

- The ones relating to role-play disturbance (B2), it can be a difficulty in understanding the role assigned to oneself and especially the actions he should execute in the game [13], to erroneous actions for the assigned role when the player disturbs the realism of the simulation forcing the other players to ignore the mistake so as not to exit the simulation [20], to a conflict between the life experience of the player and the role assigned in the game when the player becomes recognized in the game more as the player rather than as his character [20], to a conflict of authority between players, or to a shift between the role assigned to a player and the role he 
assumes when a player takes on consciously or not a role different to the one he was assigned;

- The ones relating to the level of difficulty (B3) which shows that the players stay conscious of the fact that the incidents they are dealing with are the results of the will of the team running the simulation, this level of difficulty can appear excessive or unrealistic, becomes a justification to enter gamer mode if the players bends their will to counteract the actions of the team running the simulation rather than act in a realistic manner, creates some attempts at cheating by using solution that are not in the scope of the game, or creates in the players a pressure to perform and make every effort to conform the supposed expectations of the team running the simulation.

\begin{tabular}{|l|l|c|c|c|c|}
\hline \multicolumn{2}{|c|}{} & \multicolumn{2}{|c|}{$\begin{array}{c}\text { Simulation } \\
16 \text { V2017 }\end{array}$} & \multicolumn{2}{c|}{$\begin{array}{c}\text { Simulation } \\
15 \text { VI2017 }\end{array}$} \\
\cline { 3 - 6 } & Number & Percent & Number & Percent \\
\hline \multirow{2}{*}{$\begin{array}{l}\text { A. Game } \\
\text { Nnvironnement }\end{array}$} & A1. Liminal space-time & 6 & $12 \%$ & 4 & $4 \%$ \\
\cline { 2 - 6 } & A2. Dissonances & 8 & $16 \%$ & 28 & $28 \%$ \\
\cline { 2 - 6 } & A3. Stepping away from the game & 10 & $20 \%$ & 24 & $24 \%$ \\
\hline $\begin{array}{l}\text { B. In-game } \\
\text { attitudes }\end{array}$ & B1. Pleasure from play & 12 & $24 \%$ & 15 & $15 \%$ \\
\cline { 2 - 6 } & B2. Role-play disturbance & 9 & $18 \%$ & 8 & $8 \%$ \\
\cline { 2 - 6 } & B3. Levels of difficulty & 5 & $10 \%$ & 21 & $21 \%$ \\
\hline \multicolumn{2}{|c|}{ Total } & 50 & $100 \%$ & 100 & $100 \%$ \\
\hline
\end{tabular}

Fig. 4. Distribution of the manifestations of the ludicity in the two simulations observed

Some of these components stabilize the liminal space (A1 and B1), others destabilize it (A2 and B2) and the lasts drain it (A3 and B3).

\subsection{Sensitivity of Ludicity to the Injection of an Event}

The team running the simulation tries to optimise the involvement of the players in the simulation by injecting in it various events. We observe that these injections:

- Integrate a big part of the group of players in the same type of ludicity (73\% on average over 5 injections) when the liminal space is little to not frayed (13\% of A2ludicity, $8 \%$ of A3-ludicity) but activate a reduced number of the players (45\% on average over 7 injections) when the liminal space is frayed (24\% of A2-ludicity, $24 \%$ of A3-ludicity),

- Create little in depth playful effects, the manifestations of ludicity lasting no more than a minute after the injection unless it brings information of extreme gravity (a child disappearance) then creating ludicity for the next 2 to $3 \mathrm{~min}$,

- Create many stabilizing effects on the liminal space (41\% of A1 and B1-ludicity within $1 \mathrm{~min}$ ), many destabilizing effects (34\% of A2 and B2-ludicity) and even destructive effects (25\% of A3 and B3-ludicity) which leads to question the costbenefit ratio of such interventions in the simulation, 
- Are directly responsible for only $25 \%$ to $33 \%$ of the total $2 \mathrm{D}$-ludicity detected, the remainder (67\% to $75 \%$ ) arising spontaneously during the simulation.

These results are not statistically significant enough to create a general rule but they should be seriously considered by the creators of simulation as to the undesirable side effects of the injection of events.

\subsection{Entropy and the Persistence of Ludicity}

The analysis of the simulations we observed shows (Fig. 5) that most of the stabilizing effects happen at the beginning (A1) and the end (B1) of the simulation but little in its middle half, whereas the destabilizing effects (A2 and B2) mainly happen in this middle half of the simulation. As for the effect draining the liminal space (A3 and B3) they tend to accumulate in the later half or later third of the simulation.

These analysis suggest a form of entropy is present in the organization of the liminal space. Once the liminal space is in place at the beginning of the simulation, it faces destabilizing effects which little by little drains and fragments it. Further investigations should be carried out to analyze how the disturbing events affect the players' engagement [27].

The ending of the simulation on a happy note wished by the team running the simulation (here the missing child is found) creates very different results among the players: it can restore the integrity of the liminal space or amplify its fragmentation.

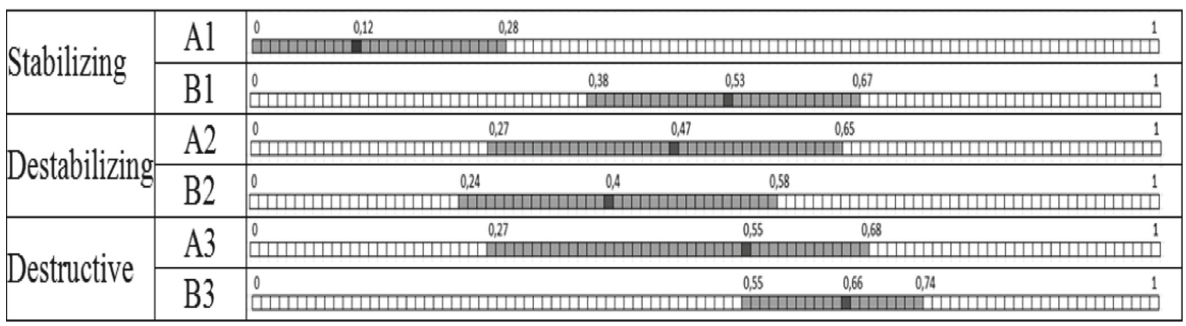

Fig. 5. Average parts of the simulation where ludicity appears (percent of the total legth)

\section{Conclusions and Discussion}

We have created a protocol to identify and do a qualitative analysis [24] of some recorded sequences of the crisis management exercise during which this ludicity, though emotional outbursts [20], manifests itself without any possible doubt. We have defined this ludicity as the emotional component of the simulation created by the players on top of what is needed for the good progress of the simulation [5].

This protocol, tested with two crisis management exercises, enabled us to verify the consistency of the ludicity which appears in at least a third of the total length of these simulations and to which close to an eighth of the ressources deployed by the players in the simulation, are dedicated. By the way our protocol is made, which identify only the 
emotional outbursts, these metrics underestimate the real consistency of ludicity. It also helped us to propose a typology of the components of ludicity with 6 main components further separated into 28 items helping us to codify the manifestations of lucidity.

The analysis done using this codification, without being statistically significant enough to create general rules, suggests that the injection of events in a simulation with which the team running the simulation hopes will influence its progress, have an effect on only a minor part of the simulation and may threaten the liminal space. To the extent that it is possible the effects created by the injection do not reflect an effort at crisis management but the effort of a group of players facing a problem with the assumed rules of the game.

They also suggest that the liminal space is built at the very beginning of the simulation, then is subject to a growing entropy which implacably disorganize it, up to the final crucial moment, the happy ending wished by the team running the simulation, when the credibility of the simulation is either mostly restored or annihilated.

We are deeply aware of the fact that we obviously by-passed the usual sophisticated definitions of emotions, extrasec or intrinsec motivation, engagement, presence, $\ldots$ that structure the theoric analysis of engagement. Our main objective was to focus on what could be observed in the simulation. The work should be carried on to refine the typology and take more benefit from theoric approachs.

Aknowledgements. The author thanks the LGEI team for recording the simulations and Matt Schoepfer for his precious support.

\section{References}

1. Raghothama, J., Meijer, S.: Rigor in gaming for design: conditions for transfer between game and reality. Simul. Gaming 49, 246-262 (2018). https://doi.org/10.1177/ 1046878118770220

2. Harviainen, J.T., Lieberoth, A.: Similarity of social information processes in games and rituals: magical interfaces. Simul. Gaming 43(4), 528-549 (2012). https://doi.org/10.1177/ 1046878110392703

3. Harviainen, J.T.: Ritualistic games, boundary control and information uncertainty. Simul. Gaming 43(4), 506-527 (2012)

4. Klabbers, J.H.G.: On the architecture of game science. Simul. Gaming 49(3), 207-245 (2018)

5. Goutx, D., Sauvagnargues, S., Mermet, L.: Managing the Game Within Crisis Exercises (2018). https://doi.org/10.1002/9781119557869.ch6

6. Henriot, J.: Sous couleur de jouer, la métaphore ludique. Ed. José Corti (1989)

7. Suits, B.: The Grasshopper. Games, Life, and Utopia. 3rd edn. Broadview Press (2014)

8. Alsawaier, R.S.: The effect of gamification on motivation and engagement. Int. J. Inf. Learn. Technol. 35(1), 56-79 (2018). https://doi.org/10.1108/IJILT-02-2017-0009

9. Csikszentmihalyi, M.: Flow: The Psychology of Optimal Experience. Haper \& Row, New York (1990)

10. Nakamura, J., Csikszentmihalyi, M.: The concept of flow. In: Snyder, C.R., Lopez, S. J. (eds.) Handbook of Positive Psychology, pp. 89-105. Oxford University Press, New York (2002) 
11. Bonenfant, M., Philippette, T.: Rhétorique de l'engagement ludique dans des dispositifs de ludification. Sciences du jeu (en ligne), 10/2018, mis en ligne le 30 octobre 2018, consulté le 28 novembre 2018 (2018). https://journals.openedition.org/sdj/1422. https://doi.org/10.4000/ sdj. 1422

12. Alvarez, J., Djaouti, D.: Introduction au Serious game. Éditions: Questions théoriques (2010)

13. Kapp, S.: L'immersion fictionnelle collaborative. Une étude de la posture d'engagement dans les jeux de rôles grandeur nature. Sociologie. Ecole des Hautes Etudes en Sciences Sociales (EHESS); Université Libre de Bruxelles, Français (2013)

14. Tychsen, A., McIlwain, D., Brolund, T., Hitchens, M.: Player-character dynamics in multiplayer role playing games. In: Proceedings of the Digital Games Research Association Conference: Situated Play, pp. 40-49. Digital Games Research Association (DiGRA) (2007)

15. Shernoff, D., Tonks, S., Anderson, B.: The impact of the learning environment on student engagement in high school classrooms. Natl. Soc. Study Educ. 113(1), 166-177 (2014)

16. Mullins, J.K., Sabherwal, R.: Beyond enjoyment: a cognitive-emotional perspective of gamification. In: Proceedings of the 51st Hawaii International Conference on System Sciences (2018). https://hdl.handle.net/10125/50039

17. DiGirolamo, M.A., Russell, J.A.: The emotion seen in a face can be a methodological artifact: the process of elimination hypothesis. J. Am. Psychiol. Assoc. 17(3), 538-546 (2017)

18. Lonsdorf, T.B., et al.: Don't fear 'fear conditioning': methodological considerations for the design and analysis of studies on human fear acquisition, extinction, and return of fear. Neurosci. Behav. Rev. 77, 247-285 (2017)

19. Jones, K.: Fear of emotions. Simul. Gaming 35(4), 454-460 (2004)

20. Goffman, E.: Encounters: Two Studies in the Sociology of Interaction. Bobbs-Merrill Company, Inc., Indianapolis (1961)

21. Dautun, C.: Thesis: Contribution to the study of large-scale crises: Knowledge and Decision Support for Civil Security. Ecole Nationale Supérieure des Mines, Saint-Etienne, France, p. 271 (2007). (in French)

22. Tena-Chollet, F.: Elaboration d'un environnement semi-virtuel de formation à la gestion stratégique de crise basé sur la simulation multi-agents. Ph.D. thesis, Ecole Nationale Supérieure des Mines de Saint-Etienne, France (2012)

23. Schubert, C.: Video analysis of practice and the practice of video analysis. In: Knoblauch, H., Schnettler, B., Raab, J., Soeffner, H.G. (eds.) Video Analysis Methodology and Methods: Qualitative Audiovisual Data Analysis and Sociology. Peter Lang (2009)

24. Knoblauch, H., Schnettler, B., Raab, J., Soeffner, H.-G.: Video Analysis: Methodology and Methods. Qualitative Audiovisual Data Analysis in Sociology, 3rd edn. Peter Lang Internationaler Verlag der Wissenschaften (2012)

25. Huizinga, J.: Homo ludens, essai sur la fonction sociale du jeu, Gallimard, 1988 (1938). ISBN 9782702204658

26. Laurent, M., Nathalie, Z.-R. (dir.): Au prisme du jeu. Concepts, pratiques, perspectives, Paris, Hermann, series: «Société» (2015)

27. Nygren, E.L., Laine, T.H., Suttinen, E.: Dynamics between disturbances and motivations in educational mobile games. Int. J. Interact. Mob. Technol. 12(3), 120-141 (2018) 